\title{
Genetic Identification and Risk Factor Analysis of Asymptomatic Bacterial Colonization on Cardiovascular Implantable Electronic Devices
}

\author{
Xian-Ming Chu, ${ }^{1}$ Bing Li, ${ }^{2}$ Yi An, ${ }^{1}$ Xue-Bin Li, ${ }^{3}$ and Ji-Hong Guo ${ }^{3}$ \\ ${ }^{1}$ Department of Cardiology, The Affiliated Hospital of Qingdao University, Qingdao 266100, China \\ ${ }^{2}$ Department of Biology, Medical College of Qingdao University, Qingdao 266021, China \\ ${ }^{3}$ Department of Cardiac Electrophysiology, Peking University People’s Hospital, Beijing 100044, China \\ Correspondence should be addressed to Xian-Ming Chu; chuxianming@medmail.com.cn
}

Received 13 May 2014; Revised 17 August 2014; Accepted 19 August 2014; Published 2 November 2014

Academic Editor: James Kirkpatrick

Copyright (C) 2014 Xian-Ming Chu et al. This is an open access article distributed under the Creative Commons Attribution License, which permits unrestricted use, distribution, and reproduction in any medium, provided the original work is properly cited.

\begin{abstract}
Asymptomatic bacterial colonization of cardiovascular implantable electronic devices (CIEDs) is widespread and increases the risk of clinical CIED infection. The aim of the study was to evaluate the incidence of bacterial colonization of generator pockets in patients without signs of infection and to analyze the relationship with clinical infection and risk factors. From June 2011 to December 2012, 78 patients underwent CIED replacement or upgrade. Exclusion criteria included a clinical diagnosis of CIED infection, bacteremia, or infective endocarditis. All patients were examined for evidence of bacterial 16S rDNA on the device and in the surrounding tissues. Infection cases were recorded during follow-up. The bacterial-positive rate was $38.5 \%$ ( 30 cases); the coagulase-negative Staphylococcus detection rate was the highest (9 cases, 11.5\%). Positive bacterial DNA results were obtained from pocket tissue in $23.1 \%$ of patients (18 cases), and bacterial DNA was detected on the device in $29.5 \%$ of patients (23 cases). During follow-up (median 24.6 months), two patients $(6.7 \%, 2 / 30)$ became symptomatic with the same species of microorganism, S. aureus and S. epidermidis. Multivariable logistic regression analysis found that the history of bacterial infection, use of antibiotics, application of antiplatelet drugs, replacement frequency, and renal insufficiency were independent risk factors for asymptomatic bacterial colonization.
\end{abstract}

\section{Introduction}

Cardiovascular implantable electronic devices (CIEDs) have been used since 1950s and have helped save the lives of many patients. A recent survey involving 61 countries indicated that in 2009 the number of implanted pacemakers was 1,002,664 with 264,824 being replaced and the number of implanted cardioverter-defibrillators was 328,027 with 105,620 being replaced [1]. However, consequent CIED-related infection has become a difficult problem which is difficult to diagnose and treat and expensive and is associated with a high fatality rate. In addition, the removal of CIEDs and electrode wires is a high-risk operation. Recently it has been reported that the occurrence rate of CIED infection was 1 7\% [2-4]. To effectively control CIED infection, it is necessary to discover the risk factors for CIED infection and to provide a specific prevention strategy.

Bacterial biofilms and bacterial colonization on the surface of implanted devices in vivo might lead to clinical infection [5-8]. Recent research revealed that asymptomatic bacterial colonization on CIEDs might be ubiquitous and increase the risk of clinical CIED infection [9-12]. Early diagnosis of patients with asymptomatic bacterial colonization is an important basis to apply specific preventative measures and to reduce clinical CIED infection. In the present study, bacterial identification based on the 16S rRNA gene was carried out to study the bacteria in pocket tissues and on the surface of the impulse generator in patients with replacement of CIEDs. The relationship between related risk factors of bacterial colonization and clinical CIED infection was also analyzed. 


\section{Methods}

2.1. Patients. A total of 78 patients who had replaced or upgraded CIEDs between June 2011 and December 2012 were enrolled consecutively. Patients who were clinically diagnosed with CIED infection, including pocket infection, bacteremia, and infective endocarditis, were excluded. Clinical characteristics and laboratory examination results were collected. The prospective registration and follow-up were carried out. Based on the Declaration of Helsinki, all patients signed medical informed consent forms to participate in this study, and the study was approved by the Ethics Committee of the Affiliated Hospital of Qingdao University.

2.2. Collection of Clinical Characteristics. The following characteristics were collected: age, gender, body mass index, reason of replacing or implanting the CIED, date of implantation, frequency of replacement, usage of temporary pacemaker, and type of the pacemaker. Past medical history included coronary heart disease, hypertension, atrial fibrillation, diabetes, renal insufficiency, chronic systolic heart failure, and chronic obstructive pulmonary disease (COPD). Bacterial infection history in the past five years contained upper respiratory infection, lower respiratory infection, urinary system infection, soft tissue infection, digestive system infection, and infection in other parts. The history of surgery in the past five years that required hospitalization was also recorded. Medication history was composed of immunosuppressive agents, anticoagulant drugs (warfarin), antiplatelet drugs (aspirin or clopidogrel), intravenous antibiotics, and oral antibiotics. Laboratory examinations consisted of ejection fraction, white blood cell count, $\mathrm{C}$ reactive protein, hemoglobin, total serum protein, and albumin.

The comorbidities included diabetes, renal insufficiency (glomerular filtration rate $<60 \mathrm{~mL} / \mathrm{min} \times 1.72 \mathrm{~m}^{-2}$ ), systolic heart failure (NYHA $\geq$ II class, ejection fraction $<45 \%$ ), and chronic heart disease (diagnosed coronary heart disease, NYHA classes III and IV, or hypertension that need to be treated by $\geq 3$ drugs). Antibiotic therapy was defined as any sequential oral or intravenous antibiotic therapy more than seven days in the past five years.

2.3. Collection of Specimens. During the replacing operation, $0.5 \mathrm{~g}$ of the pocket tissue was sampled and biofilms on the surface of the CIED were collected using a sterile scalpel. All the specimens were reserved in sterile containers and immediately preserved at $-80^{\circ} \mathrm{C}$.

2.4. Bacterial Genetic Determination [13]. Pocket tissues and the samples obtained from generators surface were washed with phosphate buffer solution (PBS) and genomic DNA was extracted using Wizard genomic DNA extraction kit (Promega, USA) according to the manufacturer's protocol.

In order to accurately determine the bacteria in the sample, universal primers (upstream primer: AGAGTTTGATCCTGGCTCAG; downstream primer: AGTAAGGAGGTGATCCAACCGCA) were designed to target the conserved region of the 16S rRNA gene (rDNA) according to Escherichia coli (GenBank J01695), which could amplify nearly all bacteria by PCR (7700, Perkin Elmer, USA). The positive band indicated the presence of bacteria in the sample. The PCR product was purified using Wizard PCR Preps DNA Purification System (Promega) and then ligated into the pGEM-T Easy Vector (Promega). The ligation product was transformed into the E. coli strain JM109. Colonies containing the inserted 16S rRNA gene inserts were identified using blue/white screening. Plasmid DNA from candidate colonies was extracted and restricted with EcoRI. The inserted $16 \mathrm{~S}$ rRNA gene sequence was then sequenced and identified by the BLAST algorithm against EMBL and GenBank databases.

2.5. Clinical Procedure. Routine checks included a chest Xray and a cardiac color ultrasound. Before the operation, routine blood tests were carried out. The first generation of cephalosporin antibiotics was injected once before operation and persisted for $72 \mathrm{~h}$ after the operation. Patients were subjected to a chest X-ray, wound check, and routine pacemaker program control follow-up before leaving the hospital one week after the operation. Routine follow-up was carried out for all patients every three months after the operation (16-34 months).

2.6. Criteria of CIED Infection during Follow-Up. Clinical symptoms included local inflammation in the pocket tissue, such as erythema, fever, fluctuation, wound dehiscence, decay, tenderness, and suppuration. The diagnosis of infective endocarditis was in accordance with the European Society of Cardiology (ESC) criteria [14]. Verified CIED infection by the same microbes was based on the identification of microbes in the operation and the culture result after infection.

2.7. Statistical Analysis. Normally distributed continuous variables were expressed as means \pm SD and continuous variables of skewed distribution were expressed as median values. Comparison between two continuous variables of normal distribution was carried out using the $t$-test. Comparison of classified variables was performed by the chi-square test or Fisher's exact test. Correlation between clinical characteristics and CIED asymptomatic bacterial colonization was analyzed by the multivariate logistic regression analysis. The software used for statistical analysis was SPSS18.0.

\section{Results}

3.1. PCR Amplification Results of the $16 S$ rRNA Gene from Partial Patients. The amplified fragment length was $1532 \mathrm{bp}$ just as shown in Figure 1.

3.2. Identification Results of Restriction Enzyme Digestion of Recombinant Plasmid. Figure 2 showed the identification results of restriction enzyme digestion of recombinant plasmid.

3.3. Identification Results of the Bacterial $16 S$ rRNA Gene Are Shown in Tables 1 and 2. Bacteria were detected in $38.5 \%$ of 78 patients, among which $23.1 \%$ were found in pocket tissues and $29.5 \%$ in biofilms. The percentage of coagulase-negative Staphylococcus was the maximum. In total, eleven patients 


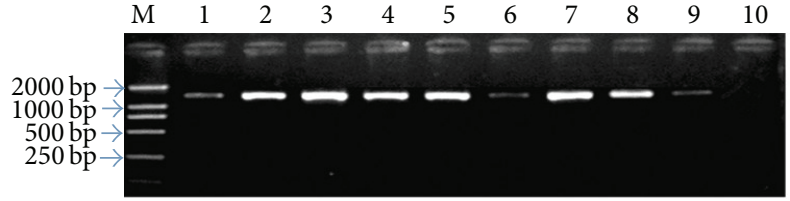

FIGURE 1: UP-PCR results of some patients. We have detected all the patients and finally we chose some positive bacteria and carried out the electrophoresis, so every line had PCR products. The deeper the stripe, the more the bacteria. Lines 1-9 represented PCR product of the 16S rRNA gene of Staphylococcus aureus, Staphylococcus epidermidis, Pseudomonas aeruginosa, Escherichia coli, Streptococcus viridans, Staphylococcus saprophyticus, Corynebacterium parvum, Klebsiella pneumoniae, and Enterobacter cloacae; M for DL2000 DNA Marker; ten for negative control.

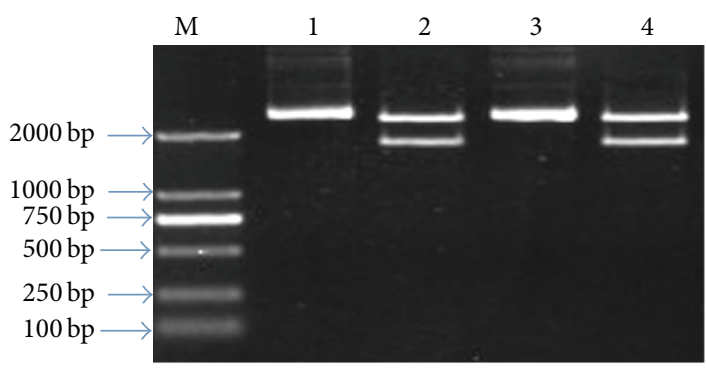

FIGURE 2: Identification of enzyme digestion of $16 \mathrm{~S}$ rRNA gene recombinant. 1, 3: enzyme-digested product of 16S rRNA gene recombinant plasmid; 2, 4: blank pGEM-T plasmid; M for DL2000 DNA Marker.

TABLE 1: DNA results of 78 patients.

\begin{tabular}{lcc}
\hline Specimen & Positive number $(n)$ & Percentage (\%) \\
\hline Overall & 30 & 38.5 \\
Pocket tissue & 18 & 23.1 \\
Surface of device & 23 & 29.5 \\
Both specimens & 11 & 14.1 \\
\hline
\end{tabular}

were positive in both pocket tissues and biofilms, of which the bacteria of two patients were inconsistent in pocket tissues and biofilms, one of E. coli and Corynebacterium parvum and another of Pseudomonas aeruginosa and S. epidermidis.

\subsection{Single Factor Analysis of Asymptomatic Bacterial Colo- nization Risk Factors. See Tables 3, 4, and 5.}

3.5. Multivariate Logistic Regression Analysis of Asymptomatic Bacterial Colonization Risk Factors. See Table 6.

3.6. Clinical Follow-Up. All patients were viable during the follow-up period with no deaths. The median follow-up time was 24.6 months (range, 16-34 months; mean, $25.6 \pm 5.8$ ). Two patients $(6.7 \%, 2 / 30)$ in the group of positive bacterial detection presented with CIED infection, which occurred 3 and 11 months after the operation, respectively. In the two patients, when CIED was replaced, the bacterial identification
TABLE 2: Bacterial species determined by DNA technology $(n, \%)$.

\begin{tabular}{lcc}
\hline Species & $\begin{array}{c}\text { Positive number } \\
(n)\end{array}$ & $\begin{array}{c}\text { Percentage } \\
(\%)\end{array}$ \\
\hline Staphylococcus aureus & 1 & 3.3 \\
Coagulase-negative Staphylococcus & 9 & 30.0 \\
$\quad$ S. epidermis & 4 & 13.3 \\
S. saprophyticus & 2 & 6.7 \\
S. warneri & 2 & 6.7 \\
S. hominis & 1 & 3.3 \\
Streptococcus viridans & 2 & 6.7 \\
Pseudomonas aeruginosa & 3 & 10.0 \\
Propionibacterium acnes & 3 & 10.0 \\
Corynebacterium parvum & 4 & 13.3 \\
Klebsiella pneumoniae & 2 & 6.7 \\
Enterobacter cloacae & 3 & 10.0 \\
Escherichia coli & 4 & 13.3 \\
Acinetobacter baumannii & 1 & 3.3 \\
\hline
\end{tabular}

TABle 3: Baseline characteristics of 78 patients.

\begin{tabular}{lcccc}
\hline & $\begin{array}{c}\text { DNA } \\
\text { positive } \\
(n=30)\end{array}$ & $\begin{array}{c}\text { DNA } \\
\text { negative } \\
(n=48)\end{array}$ & $\chi^{2}$ & $P$ \\
\hline Age & $69.1 \pm 15.2$ & $67.8 \pm 17.1$ & 1.0838 & 0.2819 \\
Gender & 17 & 23 & & \\
$\quad$ Male & 13 & 25 & & \\
$\quad$ Female & & & 0.707 & 0.702 \\
PM indications & 14 & 20 & & \\
$\quad$ SSS & 10 & 21 & & \\
$\quad$ AVB & 6 & 7 & & \\
$\quad$ AF with long intervals & & & Fisher & 0.004 \\
Replacement time & 22 & 46 & & \\
$\quad$ time & 6 & 2 & & \\
2 times & 2 & 0 & & \\
3 times & & & Fisher & 1.0 \\
PM types & 10 & 15 & & \\
Single chamber & 19 & 31 & & \\
Double chamber & 1 & 2 & & \\
ICD/CRT & 3 & 2 & Fisher & 0.381 \\
Temporary PM application & 3 & & & \\
\hline
\end{tabular}

PM, pacemaker; SSS, sick sinus syndrome; AVB, atrioventricular block; AF, atrial fibrillation with long intervals.

results were $S$. aureus and $S$. epidermidis, in line with the cultural results after infection. The patient infected with $S$. aureus had a diagnosis of cancer. Ultrasound confirmed wire vegetations and infective endocarditis with a positive blood culture. The other patient with pocket infection showed red, swollen, and diabrotic symptoms. The result of tissue culture was $S$. epidermidis, but the blood culture was negative. 
TABLe 4: Physiological characteristics of 78 patients.

\begin{tabular}{lccr}
\hline & DNA positive $(n=30)$ & DNA negative $(n=48)$ & $t$ \\
\hline Body mass index & $25.22 \pm 4.78$ & $26.02 \pm 4.02$ & 0.7974 \\
White blood cells $\left(\times 10^{9} / \mathrm{L}\right)$ & $6.23 \pm 2.1$ & $6.06 \pm 2.2$ & 0.34 \\
Blood platelets $\left(\times 10^{9} / \mathrm{L}\right)$ & $230.24 \pm 40.21$ & $226.98 \pm 35.78$ & 0.4277 \\
Hemoglobin $(\mathrm{g} / \mathrm{L})$ & $135.46 \pm 8.94$ & $136.59 \pm 8.08$ & 0.3748 \\
Total serum protein $(\mathrm{g} / \mathrm{L})$ & $63.66 \pm 6.58$ & $64.28 \pm 6.69$ & 0.5793 \\
Serum albumin $(\mathrm{g} / \mathrm{L})$ & $42.64 \pm 4.03$ & $44.05 \pm 4.12$ & 0.4031 \\
Ejection fraction $(\mathrm{EF} \%)$ & $54.68 \pm 8.76$ & $56.69 \pm 7.49$ & 0.7088 \\
\hline
\end{tabular}

TABLE 5: Comorbidities and drug application.

\begin{tabular}{lcccc}
\hline & $\begin{array}{c}\text { DNA } \\
\text { positive } \\
(n=30)\end{array}$ & $\begin{array}{c}\text { DNA } \\
\text { negative } \\
(n=48)\end{array}$ & $\chi^{2}$ & $P$ \\
\hline Chronic heart disease & 12 & 14 & 0.669 & 0.413 \\
Coronary heart disease & 8 & 10 & 0.216 & 0.642 \\
Hypertension & 14 & 22 & 0.02 & 0.886 \\
Atrial fibrillation & & & Fisher & 0.631 \\
$\quad$ Paroxysmal & 6 & 5 & & \\
$\quad$ Persistent & 3 & 6 & & \\
$\quad$ Permanent & 3 & 5 & & \\
Dilated cardiomyopathy & 6 & 6 & Fisher & 0.526 \\
Diabetes & 7 & 8 & 0.372 & 0.542 \\
Renal insufficiency & 6 & 2 & Fisher & 0.053 \\
Chronic systolic HF & 6 & 11 & & 0.672 \\
COPD & 2 & 3 & Fisher & 1.0 \\
Immunosuppressor & 1 & 2 & Fisher & 1.0 \\
Warfarin & 1 & 2 & Fisher & 1.0 \\
Antiplatelet drug use & 20 & 15 & 8.026 & 0.005 \\
Antibiotic use & 11 & 3 & 10.741 & 0.001 \\
Malignancy & 1 & 1 & Fisher & 1.0 \\
Bacterial infection history & 29 & 11 & 36.787 & 0.0001 \\
Surgical history & 3 & 4 & Fisher & 1.0 \\
\hline
\end{tabular}

HF, heart failure; COPD, chronic obstructive pulmonary disease.

\section{Discussion}

Although application of CIED is beneficial, it can lead to serious complications such as infection $[2-4,15,16]$. Replacement of CIED or repeated interventional treatments can increase the probability of infection [2-4]. Harcombe et al. have reported that the probability of infection after the replacement of CIED was about five times more than that after the first implantation [17]. Several hypotheses could explain an equilibrium between the human host and bacteria [18]. When the balance is broken, bacteria are destroyed or infection occurs. Many factors may influence this balance, such as the number of bacteria or the addition of a new infection, the virulence of bacteria and their ability to adapt to the unfavourable environment, and the defensive capacity of the host [9-12]. Repeating interventional treatments decreased patients' defense to pathogens [10].
The bacteria causing apparent pocket infection can be cultured and identified. However, as a potential infection, only $20-30 \%$ of bacteria could be identified by traditional culture-dependent methods. It is not well understood whether the pathogens are not culturable or if it is an aseptic inflammation [19-22]. Classification of pathogens used to be based on isolate, morphological, biochemical, and immunological methods which are time-consuming, poorly specific, and low sensitive. However, the 16S rRNA gene sequence analysis technology has allowed bacterial evolution to be confirmed by experimental investigation, which has revolutionized in bacterial taxonomic history. The homology of ancient 16S rRNA is high, and the gene contains both conserved and variable sequences. The molecular size of the gene is suitable to operate and the sequence variation adapts to evolutionary distance. Therefore the $16 \mathrm{~S}$ rRNA gene has been the most common and useful molecular clock in bacterial taxonomy $[20,21]$.

In the present study, the total positive rate for bacterial determination in 78 asymptomatic patients with CIED replacement reached $38.5 \%$. The major bacterium was coagulase-negative Staphylococcus (11.5\%). The high positive results were consistent with previous studies and suggested that similar ubiquitous bacterial colonization was present $[9,12,23]$. Research indicated that one-third of implantable cardioverter-defibrillator (ICD) patients were positive for microbial swab culture in pocket tissues and drawn wires when replacing generator and wires [10].

Provided that bacterial DNA was rapidly degraded after death $[24,25]$, it could be considered that the organism detected was derived from microfunctional groups but not molecular residues from contamination during the last operation. In the present study, DNA was isolated from $29.5 \%$ of biofilms on the CIED surface and $23.1 \%$ of subcutaneous pocket tissues and $14.1 \%$ from both. This result showed that microbes were easy to exist not only on the CIED but also in tissues near the CIED. During the follow-up period, $93.3 \%$ $(28 / 30)$ patients with positive bacteria had no clinical symptoms of infection. This suggested that there were uninjurious microbial communities on the generators surface. But, under some conditions, the balance was destroyed and pathogens (e.g., Staphylococcus) might lead to infection. However, the specific mechanism needed to be further verified. The bacterium growing on the skin, for example, C. parvum, was considered to be probably contaminated during sampling. 
TABLE 6: Multifactor logistic regression analysis.

\begin{tabular}{lcccccc}
\hline Risk factor & $\beta$ & SE $(\beta)$ & Wald & $P$ & OR & 95\% CI \\
\hline Bacterial infection history & 3.596 & 0.793 & 21.79 & $<0.0001$ & 36.45 & $6.85-198.231$ \\
Antibiotic use & 2.104 & 0.695 & 7.934 & 0.004 & 8.198 & $2.01-30.47$ \\
Antiplatelet drug use & 1.324 & 0.474 & 7.362 & 0.005 & 3.758 & $1.287-9.645$ \\
Replacement of two times & 1.732 & 0.818 & 4,126 & 0.031 & 5.65 & $1.131-30.82$ \\
Renal insufficiency & 1.634 & 0.831 & 3.871 & 0.041 & 5.12 & $1.004-26.73$ \\
\hline
\end{tabular}

Replacement times: significant difference between 2 and 1 times, no difference between 3 and 1 times.

Previous study has shown that $S$. aureus and S. epidermidis that were detected by culture might be clinically related to deadly pathogens that caused instrument infection [2-4, $15,16]$. The present study confirmed this point. Staphylococcus were detected in 10 patients (Table 2). During follow-up, two patients $(6.7 \%)$ who were positive for bacterial determination suffered from CIED infection. The bacteria detected in the CIED replacement were identified as $S$. epidermidis and $S$. aureus, which were in accordance with the culture result after infection and shared the same antimicrobial susceptibility. The two bacteria belonged to the common bacteria in CIED infection in the previous study $[2-4,15,16]$. Therefore bacterial identification and antimicrobial susceptibility test for CIED could guide the correct antibiotic treatment. In order to kill bacteria, new treatment methods were being constantly generated. A recent study revealed that direct current could kill S. aureus in biofilms on the surface of CIEDs [26].

There are factors associated with a weakened immune response or predisposition to repetitive bacteraemias, which have been shown to predispose to the infection [27]. The risk factors include renal failure [21, 28], diabetes and congestive heart failure [21], the number of previous operations $[21,22,29]$, increasing number of leads [22], experienced bacteraemias [30], and vegetations on the leads [27, 31]. But a previous study showed that common risk factors for device infection did not correlate with the presence of DNA [9]. In the present study, analyses of risk factors related to asymptomatic bacterial colonization indicated that bacterial infection history, antibiotic history, usage of antiplatelet drugs, two replacements of CIED, and renal insufficiency were independent risk factors for asymptomatic bacterial colonization. The history of bacterial infection and antibiotic usage prompted immune dysfunction, and the patients might be repeatedly exposed to bacterial infections or bacteremia, which might increase the pathogenic bacteria migration to the surface of implants in the body. Use of antiplatelet drugs may cause microbleeding in pockets, and renal insufficiency was often associated with immune and circulation dysfunction, which might be susceptible to microbial colonization.

Repetitive operations such as replacement and upgrade of a pacemaker could easily cause infection $[3,10,32]$. The probability of infecting complications significantly increased for the patients who received treatment for a complex implantable device $[32,33]$. The infection rate was 5.5\% for the young patients that received an average of two pacemaker implanting operations, five times higher than that for the first operation [33]. Before, secondary intervention for hematomas and movement of the wire were the two factors that easily lead to infection, and the odds ratio (OR) reached up to 15.04 [33]. Harcombe et al. revealed that the occurrence rate of complications caused by the replacement of a pacemaker reached $6.5 \%$, while that caused by first implantation of the pacemaker was $1.4 \%$ [17]. The complications resulted from the erosion and infection of the implantable device [17]. In total, $80 \%$ of patients with clinical infection had received the pacemaker implanting operation on average twice or more than twice, suggesting that repeated implanting significantly increased the probability of infection. The infection probability of first implantation was $0.8 \%$ and $4 \%$ for replacement of the device $[3,17]$.

There were several hypotheses for the source and mechanism of CIED infection. One was contamination of the pocket tissue before the implanting operation. After implantation, patients' defense capabilities shifted and previously dormant bacteria massively propagated, leading to infection [18]. In total, $6.7 \%$ patients with positive bacteria were infected by the same bacteria that were also the same as the bacteria isolated from the device [10]. Under this hypothesis, asymptomatic bacterial colonization led to the infection after the devicereplacing operation, which explained why the infection rate of the second implantation was higher than that of the first. Bacterial contamination was a new problem in operations and a tough problem with more and more patients receiving ICD treatment, especially combined with cardiac resynchronization therapy devices. Bacterial contamination was related to the operating time and the number of implanted devices. The ICD patients who suffered from serious heart trouble were easier to be infected, which would affect the analysis for cost and effectiveness in ICD patients' survival time [34]. In addition, remnants of CIED in vivo might increase the risk of infection. Complete removal of all CIED hardware should be attempted at the time of upgrade and revision and even prior to orthotopic heart transplantation $[35,36]$. Furthermore, gene polymorphisms, such as fibronectin-binding protein A of S. aureus, were associated with infection of cardiovascular devices [37].

\section{Limitations}

Although bacterial DNA determination had high sensitivity, the possibility of a few false-negative results must be considered. In addition, false-positives could not be completely excluded, which might be affected by factors of the implantable device, antibiotic therapeutic regimen, 
the in vivo location of the implanting pocket, and contamination. The number of monocentric samples was limited; therefore some important issues, such as whether asymptomatic bacterial colonization on CIEDs could lead to clinical infection, could not be answered. Although quantitative PCR was used, it was impossible to quantify the bacteria completely on and around the CIED, which might be an important factor for pathogenicity. Recent research had indicated that means of sonic degradation were conducive to bacterial determination after replacement, removal, and infection [38-40].

\section{Conclusions}

There was a high proportion of asymptomatic bacteria on pacemakers or in ICD patients. The determination rate of coagulase-negative Staphylococcus was the highest. The major carried bacteria were related to common microflora in CIED infection, and bacteria rarely resulting in CIED infection were detected. The functions of these bacteria in CIED infection, for example, synergism, facilitating form of biofilm, or protection, needed further research.

\section{Conflict of Interests}

The authors declare that there is no conflict of interests regarding the publication of this paper.

\section{Acknowledgments}

This project is supported by the National Natural Science Foundation of China (nos. 81001346 and 81471546), Capital Project (no. Z121107001012016), Shandong Project (nos. 2012YD18035 and J12LL59), and Hospital Project (no. 47-11).

\section{References}

[1] H. G. Mond and A. Proclemer, "The 11th world survey of cardiac pacing and implantable cardioverter-defibrillators: calendar year 2009-a world society of Arrhythmia's project," Pacing and Clinical Electrophysiology, vol. 34, no. 8, pp. 1013-1027, 2011.

[2] R. Margey, H. McCann, G. Blake et al., "Contemporary management of and outcomes from cardiac device related infections," Europace, vol. 12, no. 1, pp. 64-70, 2010.

[3] D. Klug, M. Balde, D. Pavin et al., "Risk factors related to infections of implanted pacemakers and cardioverter-defibrillators: results of a large prospective study," Circulation, vol. 116, no. 12, pp. 1349-1355, 2007.

[4] M. G. Bongiorni, G. Marinskis, G. Y. H. Lip, J. H. Svendsen, D. Dobreanu, and C. Blomström-Lundqvist, "How European centres diagnose, treat, and prevent CIED infections: results of an European Heart Rhythm Association survey," Europace, vol. 14, no. 11, pp. 1666-1669, 2012.

[5] P. Vergidis and R. Patel, "Novel approaches to the diagnosis, prevention, and treatment of medical device-associated infections," Infectious Disease Clinics of North America, vol. 26, no. 1, pp. 173-186, 2012.

[6] N. Kanaan, A. Winkel, N. Stumpp, M. Stiesch, and T. Lenarz, "Bacterial growth on cochlear implants as a potential origin of complications," Otology and Neurotology, vol. 34, no. 3, pp. 539543, 2013.
[7] S. M. B. Azevedo, K. Z. Kantorski, L. F. Valandro, M. A. Bottino, and C. A. Pavanelli, "Effect of brushing with conventional versus whitening dentifrices on surface roughness and biofilm formation of dental ceramics," General Dentistry, vol. 60, no. 3, pp. e123-e130, 2012.

[8] J. Bak, T. Begovic, T. Bjarnsholt, and A. Nielsen, "A UVC device for intra-luminal disinfection of catheters: In vitro tests on soft polymer tubes contaminated with Pseudomonas aeruginosa, Staphylococcus aureus, Escherichia coli and Candida albicans," Photochemistry and Photobiology, vol. 87, no. 5, pp. 1123-1128, 2011.

[9] M. Pichlmaier, V. Marwitz, C. Kühn et al., "High prevalence of asymptomatic bacterial colonization of rhythm management devices," Europace, vol. 10, no. 9, pp. 1067-1072, 2008.

[10] T. Kleemann, T. Becker, M. Strauss et al., "Prevalence of bacterial colonization of generator pockets in implantable cardioverter defibrillator patients without signs of infection undergoing generator replacement or lead revision," Europace, vol. 12, no. 1, pp. 58-63, 2010.

[11] D. Klug, F. Wallet, S. Kacet, and R. Courcol, "Positive cultures in asymptomatic patients during elective device replacement: a murderer hides in the darkness or an innocent person on the crime scene?" Europace, vol. 12, no. 1, pp. 5-6, 2010.

[12] M. Pichlmaier, L. Knigina, C. Kuehn et al., “The role of cohabitant unusual bacterial species in infection of cardiovascular implantable electronic devices (CIED)," Technology and Health Care, vol. 21, no. 1, pp. 87-96, 2013.

[13] U. S. Justesen, M. N. Skov, E. Knudsen, H. M. Holt, P. Søgaard, and T. Justesen, "16S rRNA gene sequencing in routine identification of anaerobic bacteria isolated from blood cultures," Journal of Clinical Microbiology, vol. 48, no. 3, pp. 946-948, 2010.

[14] G. Habib, B. Hoen, P. Tornos et al., "Guidelines on the prevention, diagnosis, and treatment of infective endocarditis (new version 2009): the Task Force on the Prevention, Diagnosis, and Treatment of Infective Endocarditis of the European Society of Cardiology (ESC). Endorsed by the European Society of Clinical Microbiology and Infectious Diseases (ESCMID) and the International Society of Chemotherapy (ISC) for Infection and Cancer," European Heart Journal, vol. 30, no. 19, pp. 23692413, 2009.

[15] M. R. Sohail, D. Z. Uslan, A. H. Khan et al., "Management and outcome of permanent pacemaker and implantable cardioverter-defibrillator infections," Journal of the American College of Cardiology, vol. 49, no. 18, pp. 1851-1859, 2007.

[16] L. M. Baddour, A. E. Epstein, C. C. Erickson et al., "Update on cardiovascular implantable electronic device infections and their management: a scientific statement from the american heart association," Circulation, vol. 121, no. 3, pp. 458-477, 2010.

[17] A. A. Harcombe, S. A. Newell, P. F. Ludman et al., "Late complications following permanent pacemaker implantation or elective unit replacement," Heart, vol. 80, no. 3, pp. 240-244, 1998.

[18] M. J. Blaser and D. Kirschner, "The equilibria that allow bacterial persistence in human hosts," Nature, vol. 449, no. 7164, pp. 843-849, 2007.

[19] R. Lo, M. D’Anca, T. Cohen, and T. Kerwin, "Incidence and prognosis of pacemaker lead-associated masses: a study of 1,569 transesophageal echocardiograms," Journal of Invasive Cardiology, vol. 18, no. 12, pp. 599-601, 2006. 
[20] M. R. Sohail, "Management of infected pacemakers and implantable cardioverter-defibrillators," Internal Medicine Journal, vol. 37, no. 7, pp. 509-510, 2007.

[21] A. Dasgupta, J. Montalvo, S. Medendorp et al., "Increased complication rates of cardiac rhythm management devices in ESRD patients," American Journal of Kidney Diseases, vol. 49, no. 5, pp. 656-663, 2007.

[22] M. R. Sohail, D. Z. Uslan, A. H. Khan et al., "Risk factor analysis of permanent pacemaker infection," Clinical Infectious Diseases, vol. 45, no. 2, pp. 166-173, 2007.

[23] J. Dy Chua, A. Abdul-Karim, S. Mawhorter et al., "The role of swab and tissue culture in the diagnosis of implantable cardiac device infection," Pacing and Clinical Electrophysiology, vol. 28, no. 12, pp. 1276-1281, 2005.

[24] W. Emlen and M. Mannik, "Clearance of circulating DNA-antiDNA immune complexes in mice," The Journal of Experimental Medicine, vol. 155, no. 4, pp. 1210-1215, 1982.

[25] Y. M. Dennis Lo, J. Zhang, T. N. Leung, T. K. Lau, A. M. Z. Chang, and N. Magnus Hjelm, "Rapid clearance of fetal DNA from maternal plasma," The American Journal of Human Genetics, vol. 64, no. 1, pp. 218-224, 1999.

[26] E. L. Sandvik, B. R. McLeod, A. E. Parker, and P. S. Stewart, "Direct electric current treatment under physiologic saline conditions kills Staphylococcus epidermidis biofilms via electrolytic generation of hypochlorous acid," PLOS ONE, vol. 8, no. 2, Article ID e55118, 2013.

[27] B. L. Wilkoff, C. J. Love, C. L. Byrd et al., "Transvenous lead extraction: heart rhythm society expert consensus on facilities, training, indications, and patient management: this document was endorsed by the American Heart Association (AHA)," Heart Rhythm, vol. 6, no. 7, pp. 1085-1104, 2009.

[28] H. Bloom, B. Heeke, A. Leon et al., "Renal insufficiency and the risk of infection from pacemaker or defibrillator surgery," $P A C E$ - Pacing and Clinical Electrophysiology, vol. 29, no. 2, pp. 142145, 2006.

[29] A. Borer, J. Gilad, E. Hyam et al., "Prevention of infections associated with permanent cardiac antiarrhythmic devices by implementation of a comprehensive infection control program," Infection Control and Hospital Epidemiology, vol. 25, no. 6, pp. 492-497, 2004.

[30] D. Z. Uslan, M. R. Sohail, P. A. Friedman et al., "Frequency of permanent pacemaker or implantable cardioverter-defibrillator infection in patients with gram-negative bacteremia," Clinical Infectious Diseases, vol. 43, no. 6, pp. 731-736, 2006.

[31] P.-L. Massoure, S. Reuter, S. Lafitte et al., "Pacemaker endocarditis: clinical features and management of 60 consecutive cases," Pacing and Clinical Electrophysiology, vol. 30, no. 1, pp. 12-19, 2007.

[32] P. A. Gould, L. J. Gula, J. Champagne et al., "Outcome of advisory implantable cardioverter-defibrillator replacement: oneyear follow-up," Heart Rhythm, vol. 5, no. 12, pp. 1675-1681, 2008.

[33] D. Klug, G. Vaksmann, M. Jarwé et al., "Pacemaker lead infection in young patients," Pacing and Clinical Electrophysiology, vol. 26, no. 7, pp. 1489-1493, 2003.

[34] G. D. Sanders, M. A. Hlatky, and D. K. Owens, "Costeffectiveness of implantable cardioverter-defibrillators," The New England Journal of Medicine, vol. 353, no. 14, pp. 1471-1480, 2005.

[35] A. Martin, J. Voss, D. Shannon, P. Ruygrok, and N. Lever, "Frequency and sequelae of retained implanted cardiac device material post heart transplantation," Pacing and Clinical Electrophysiology, vol. 37, no. 2, pp. 242-248, 2014.

[36] M. Sohal, S. Williams, M. Akhtar et al., "Laser lead extraction to facilitate cardiac implantable electronic device upgrade and revision in the presence of central venous obstruction," Europace, vol. 16, no. 1, pp. 81-87, 2014.

[37] S. K. Lower, S. Lamlertthon, N. N. Casillas-Ituarte et al., "Polymorphisms in fibronectin binding protein A of Staphylococcus aureus are associated with infection of cardiovascular devices," Proceedings of the National Academy of Sciences of the United States of America, vol. 108, no. 45, pp. 18372-18377, 2011.

[38] P. K. Mason, J. P. Dimarco, J. D. Ferguson et al., "Sonication of explanted cardiac rhythm management devices for the diagnosis of pocket infections and asymptomatic bacterial colonization," Pacing and Clinical Electrophysiology, vol. 34, no. 2, pp. 143-149, 2011.

[39] A. Oliva, V. Belvisi, M. Iannetta et al., "Pacemaker lead endocarditis due to multidrug-resistant Corynebacterium striatum detected with sonication of the device," Journal of Clinical Microbiology, vol. 48, no. 12, pp. 4669-4671, 2010.

[40] G. F. Jost, M. Wasner, E. Taub, L. Walti, L. Mariani, and A. Trampuz, "Sonication of catheter tips for improved detection of microorganisms on external ventricular drains and ventriculoperitoneal shunts," Journal of Clinical Neuroscience, vol. 21, no. 4, pp. 578-582, 2014. 


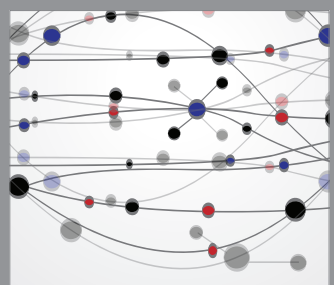

The Scientific World Journal
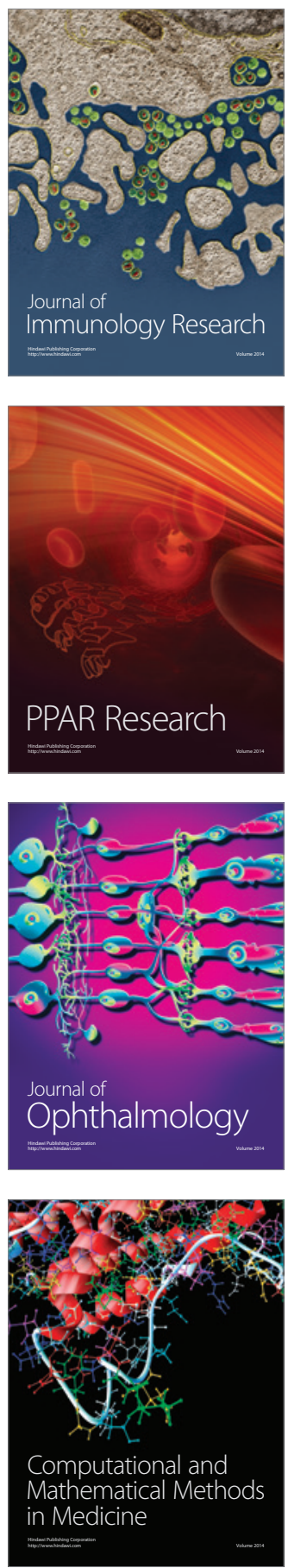

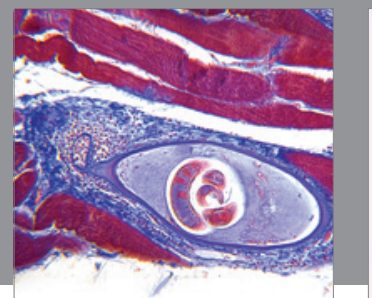

Gastroenterology

Research and Practice
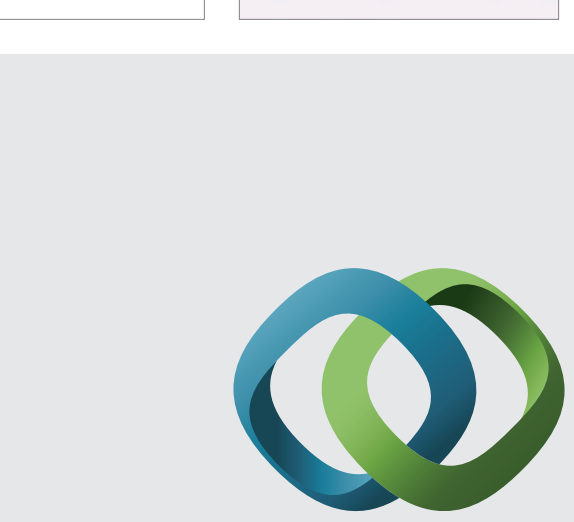

\section{Hindawi}

Submit your manuscripts at

http://www.hindawi.com
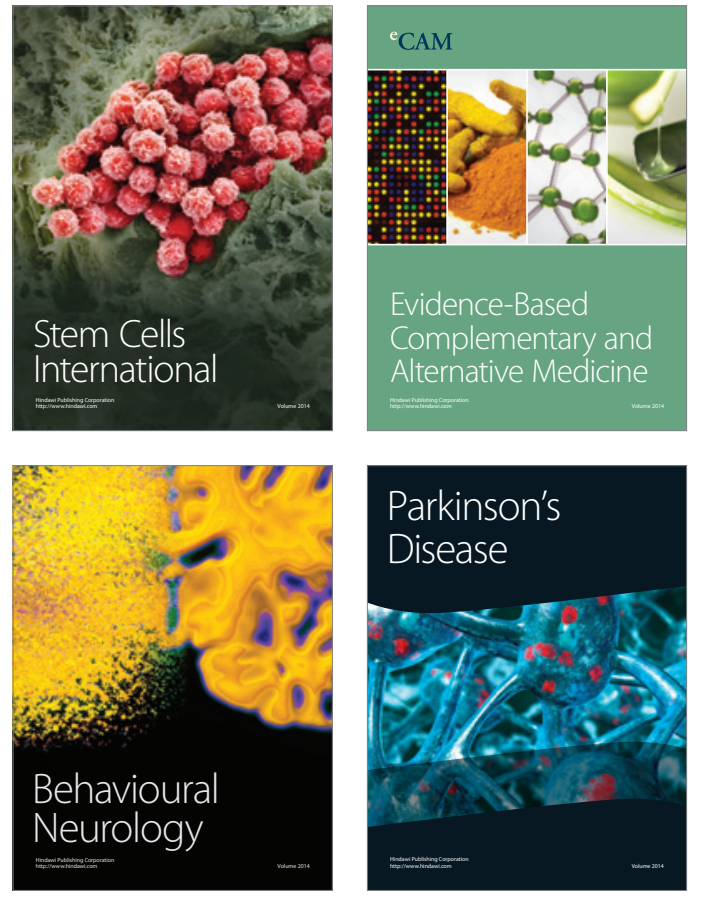
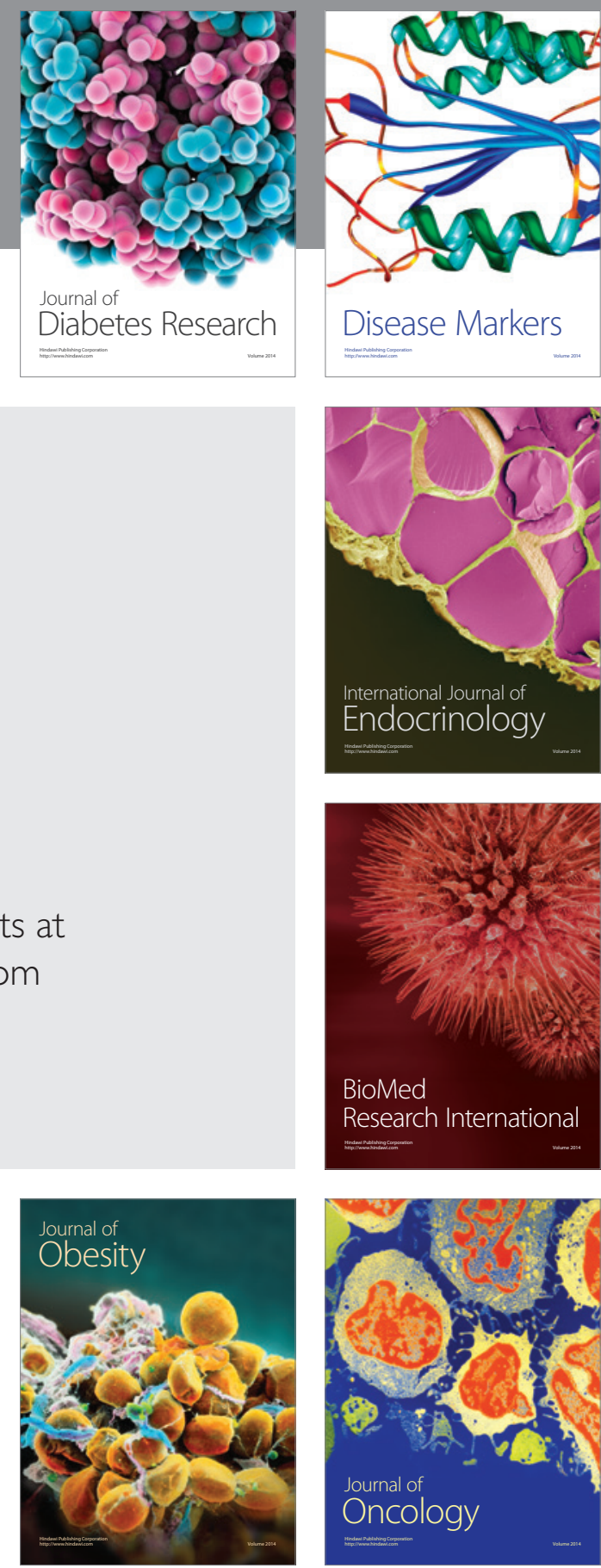

Disease Markers
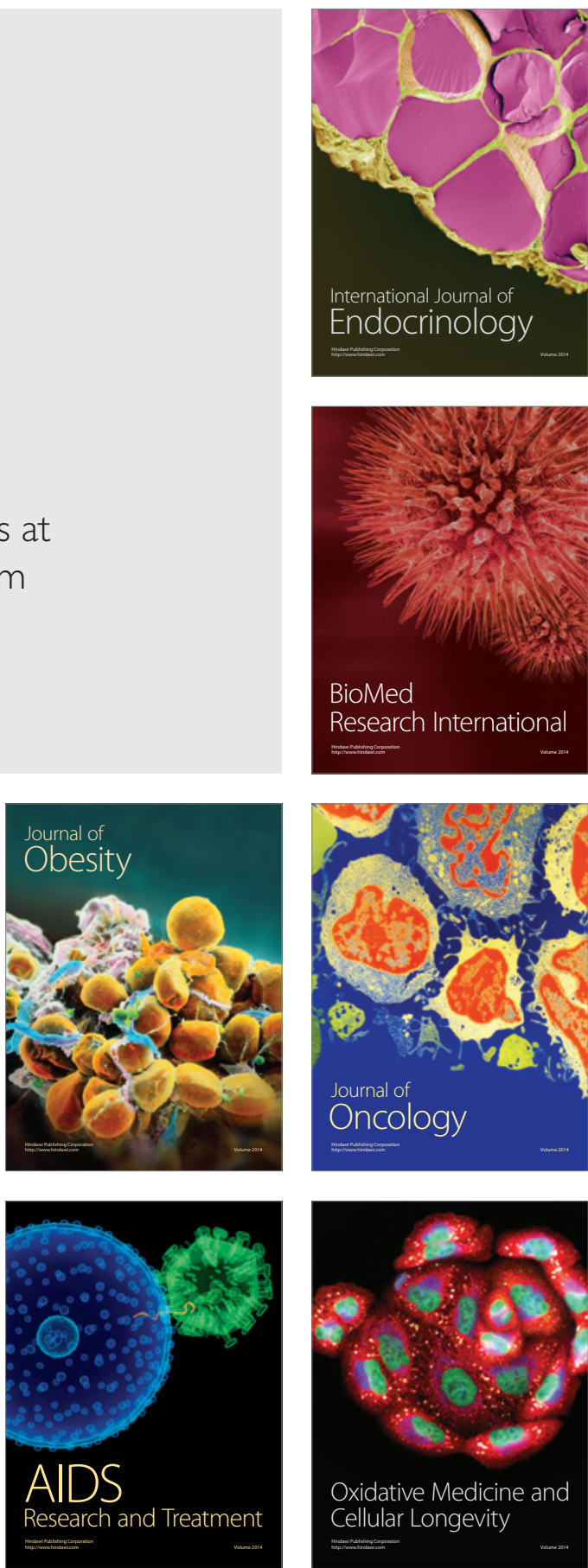